\title{
Addicted patients are at higher risk of sternal wound infection after open heart surgeries in the site of surgical incision
}

\author{
Hossein Rafiei • Hakimeh Hossein Rezaei • \\ Jafar Moghaddasi
}

Received: 5 May 2012 /Revised: 11 June 2012 / Accepted: 7 July 2012 /Published online: 19 August 2012

(C) Indian Association of Cardiovascular-Thoracic Surgeons 2012

Sternal wound infection is one of the most important complications that occur acutely or chronically after open heart surgeries. Infections are either superficial or deep in the site of the surgical incision. Among critically ill patients, incidences of substance abuse have been reported between 5 and $30 \%$ [1]. In a descriptive cross sectional study, we surveyed risk factors of sternal wound infection after open heart surgeries in the site of surgical incision in Iranian critical care units between March 2010 to March 2011. During 1 year, we studied 520 critically ill patients. Of them 89 patient were addicted. Of addicted patients, $86 \%$ were men and rests were women. Mean age of patients were 54.2 $(\mathrm{SD}=10.7)$. Approximately, $93 \%$ of the studied addicted patients had a history of myocardial infarction. All of them were addicted to a special form of opium named "Taryak" in Iran. Mean cardiac intensive care unit stay for addicted patients was 2.7 days $(\mathrm{SD}=1.7)$. Results of our study showed that incidence of sternal wound infection in the addicted patients were higher than other patients who were not addicted (19.3 vs $10 \%)$.

\section{H. Rafiei}

Department of Intensive and Critical Care, School of Nursing and Midwifery, Shahrekord University of Medical Sciences, Shahrekord, Iran

e-mail: Hosseinrafiei21@yahoo.com

\section{H. H. Rezaei $(\square)$}

Department of Medical Surgical, School of Nursing and Midwifery, Kerman University of Medical Sciences, Kerman, Iran

e-mail: hrezaee@kmu.ac.ir

\section{J. Moghaddasi}

Department of Medical Surgical, School of Nursing and Midwifery, Shahrekord University of Medical Sciences,

Shahrekord, Iran
While opiates directly modulate host immunity, their effects on physiological function of nonspecific host mechanisms are thought to also alter immune responses and play an important role in increased susceptibility to infection [2]. These effects are proposed to act through the Central Nervous System (CNS) and the hypothalamus-pituitaryadrenal axis. Opiates are known to alter the release of hypothalamus-pituitary-adrenal hormones (corticotrophinreleasing hormone and adrenocorticotrophic hormone), which, in turn, alter glucocorticoids (cortisol and corticosterone), the end-effectors of the hypothalamus-pituitaryadrenal axis [3]. The glucocorticoids play an important role in decreasing and regulating cellular immune responses [2].

Ancient Iranians believed that the use of opium reduce rate of cardiovascular diseases. Our study showed that addicted patients are at higher risk of sternal wound infection after open heart surgery. We recommended that medical and nursing team considered addiction as a risk factor that can increase stenal wound infection. Site of surgery in addicted critically ill patients who are undergoing open heart surgery should be checked carefully by nurses who caring of this group of patients after surgery.

\section{References}

1. Suchyta MR, Hopkins RO, Beck C, Jephson A. Prevalence of alcohol abuse, drug abuse and psychiatric disorders in icu patients. Am J Resp Crit Care Med. 2006;3:A737.

2. Friedman H, Newton C, Klein TW. Microbial infections, immunomodulation, and drugs of abuse. Clin Microbiol Rev. 2003;16:209-19.

3. Allolio B, Schulte HM, Deuss U, Kallabis D, Hamel E, Winkelman W. Effect of oral morphine and naloxone on pituitary-adrenal response in man induced by human corticotropin-releasing hormone. Acta Endocrinol. 1987;114:509-14. 